\title{
GRAFIČKI INTERFEJS EDUKATIVNOG ELEKTROFIZIOLOŠKOG AKVIZICIONOG UREDAJA
}

\section{USER INTERFACE OF THE ELECTROPHYSIOLOGICAL DATA ACQUISITION DEVICE FOR EDUCATIONAL PURPOSES}

\section{Oblast - ELEKTROTEHNIKA I RAČUNARSTVO}

Kratak sadržaj - U okviru ovog rada predstavljena je realizacija grafičkog korisničkog interfejsa koji je razvijen za mikrokontroler ATXMega128A1 u okruženju MikroC pro for AVR. U radu su priloženi rezultati dobijeni upotrebom dizajnirane aplikacije $i$ njihova analiza.
\end{abstract}

Žaklina Stojšin, Fakultet tehničkih nauka, Novi Sad
Ključne reči: Grafički korisnički interfejs, mikrokontroler, eletrofiziolosški signali

Abstract - This paper represents the realization for designing graphical user interface which is developed for microcontroller ATXMega128A1 in developing platform MikroC pro for AVR. It has results that are given from designed application and it's analisys.

Keywords: Graphical user interface, microcontroller, electrophysiological signals.

\section{UVOD}

Grafički interfejs predstavlja softversko okruženje koje omogućava korisniku komunikaciju sa računarom na osnovu prethodno definisanih funkcija [1]. Razvoj grafičkog korisničkog interfejsa treba da uvaži karakteristike hardverskog uređaja i dostupne softverske resurse. Pažljivo osmišljen i koncipiran grafički interfejs daje upotpunjen finalni proizvod, a istovremeno kreativni izazov za dizajnera.

Zadatak dizajnera jeste da razume mogućnosti i potrebe korisnika. Potrebno je da interfejs bude jednostavan,lak za učenje, logički organizovan sa uočljivim obeležjima i smernicama. Jednostavnost u vidu razumevanja željene funkcije i pronalaženja željene opcije olakšava upotrebu interfejsa. Veliki izazov dizajniranja interfejsa ogleda se u raznovrsnosti ljudskih sposobnosti, karakteristike ličnosti, kulture i načina rada korisnika [2].

Ekran grafičkog interfejsa treba da odlikuje funkcionalnost i složenost [3]. Uspešno dizajniran ekran treba da pruži korisniku sve podatke u pravilnom redosledu kako bi se određeni zadatak adekvatno obavio. Grafički interfejsi u medicini pružaju mogućnost brzog dijanostikovanja bolesti.

\section{NAPOMENA:}

Ovaj rad proistekao je iz master rada čiji mentor je bio dr Vojin Ilić, vanred. prof.
Praćenje stanja pacijenta omogućava se van zdravstvenih ustanova. Dodavanjem trodimenzionalnog predstavljanja, zvuka, animacija, video materijala poboljšava se izgled $i$ informativnost grafičkih interfejsa. Sve veća pažnja se pridaje aspektima upotrebljivosti interfejsa. Konstantnim usavršavanjem dizajna teži se ka postizanju krajnjeg produkta koji ima veliku brzinu rada, minimalan broj grešaka i koji pruža zadovoljstvo u radu. Prepoznatljiv stil daje lični pečat dizajniranom grafičkom interfejsu. Krajnji cilj je zadovoljavanje očekivanja korisnika $\mathrm{u}$ okviru budžeta.

U okviru rada prikazano je jedno rešenje edukativnog elektrofiziološkog sistema. Realizovan uređaj predstavlja prototip koji je prenosiv i pristupačan korisnicima. Sistem služi za akviziciju EKG i EMG signala.

\section{GRAFIČKI INTERFEJSI}

Od davnina se sve veći značaj pridaje realizaciji grafičkih interfejsa. U današnje vreme se pažnja pridaje velikoj funkcionalnosti sistema. Teži se ka realiyaciji uređaja koji ima visok kvalitet, laku prenosivost, male dimenzije i koji je ujedno jednostavan za upotrebu. U nastavku je prikazan istorijski razvoj grafičkih interfejsa, dat je primer prvog EKG uređaja i prikazani su neki od razvijenih, funkcionalnijih i savremenijih sistema.

\subsection{Telekardiogram}

Prvi EKG uredjaj je bio veoma robustan. Sastojao se od tanke žice koja se nalazila između polova potkovičastog magneta.

Prilikom prolaska struje kroz žicu, stvaralo se magnetsko polje. Dato polje je izazivalo pomeranje žice. Svetlost koja se odazirala sa žice je stvarala senku na pokretnom fotografskom papiru. Mašina je zahtevala vodeno hlađenje.

Grafički interfejs datog uređaja imao je složenu funkcionalnost, što može da se uoči na slici 1. Medicinsko osoblje je moralo biti obučeno kako bi moglo da upravlja mašinom. S obzirom na njegovu robusnost i težinu, uređaj je bio nepomičan.

Sve karakteristike ukazuju na komplikovanost snimanja EKG signala. Brzina rada uređaja i vreme učenja korisnika bile su male. 


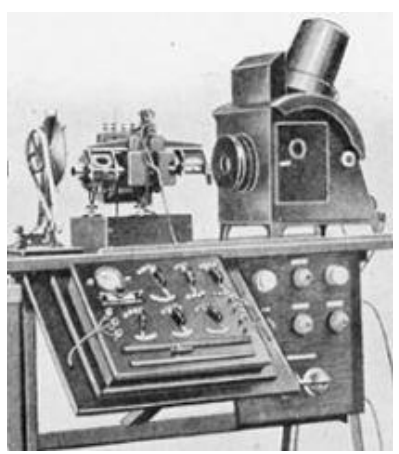

Slika 1. Grafički interfejs uređaja

\subsection{Holter monitoring uređaj}

Holter monitoring uređaj predstavlja prenosivi uređaj koji omogućava snimanje srčanog ritma pacijenta od 24 sata do 48 sati neprestano. Elektrode su postavljene na grudni koš pacijenta i povezane su za prenosivi uređaj putem žica [5]. Grafički interfejs uređaja je veoma jednostavan za upotrebu i razumevanje. Prednost njegove jednostavnosti jeste u mogućnosti upotrebe bez kompleksne obuke korisnika.

Uređaj zbog svoje jednostavnosti i funkcionalnosti se koristi van zdravstvenih ustanova. Poseduje jedan ekran na kom se vide povratne informacije snimanja, odnosno EKG signal. Sadrži dugmiće sa jasnim smernicama za upotrebu, što može da se vidi na slici 2.

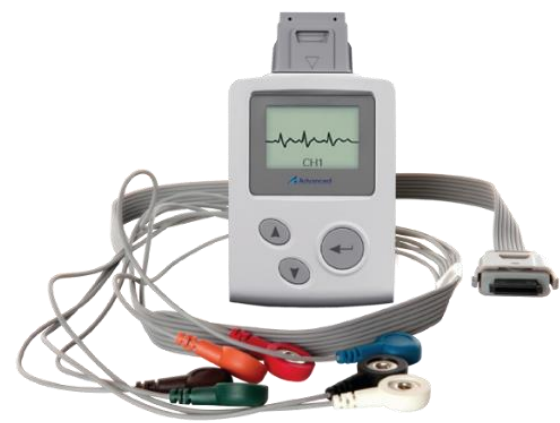

Slika 2. Grafički interfejs uređaja

\section{PROGRAMSKO OKRUŽENJE ZA RAZVOJ GRAFIČKOG INTERFEJSA}

Za dizajn aplikacije korišćeno je radno okruženje $M i k r o C$ PRVO for AVR, razvijeno od strane kompanije Mikroelektronika. Dato okruženje se koristi za programiranje mikrokontrolera u programskom jeziku C. Okruženje pruža mogućnost dizajniranja Visual TFT aplikacije. Kako bi se realizovala data mogućnost neophodno je odabrati datu opciju prilikom pravljenja novog projekta.

Nakon željenog odabira, korisniku se pružaju opcije odabira direktorijuma u kojem želi da se nalazi dati projekat i mogućnost imenovanja aplikacije. Nakon izvršenih koraka, generiše se okruženje u kom korisnik kreira kod.

Nakon što je korisnik odabrao Visual TFT project kao novi projekat, pored okruženja u kom se kreira kod, može da se pristupi i okruženju u kom se dizajniraju ekrani date aplikacije. Dato radno okruženje može da se vidi na slici 3. Postavljanje objekata na ekran se vrši jednostavnim prevlačenjem iz menija sa alatkama.

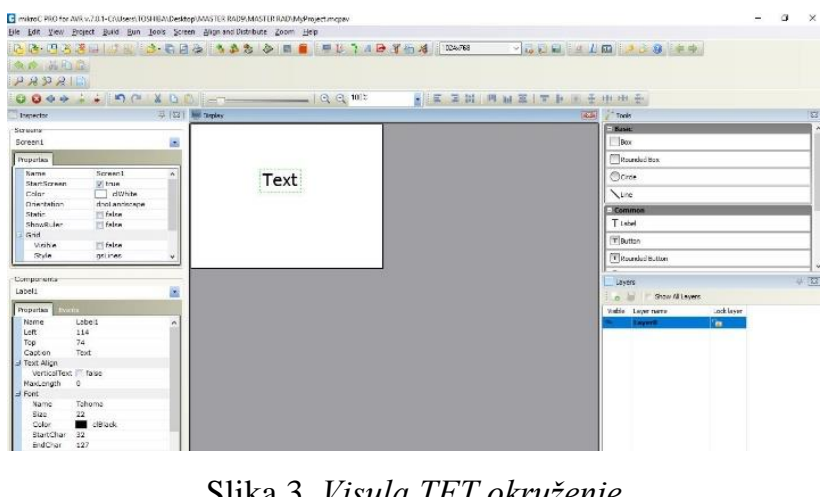

Slika 3. Visula TFT okruženje

Prozor sa alatkama, lociran u gornjem desnom uglu služi za dizajniranje ekrana. Korisnik ima mogućnost da bira između geomitrijskih oblika (Box, Rounded Box, Circle), linije (Line), labela za pisanje teksta (Label), dugmića (Button, Rounded Button, Circle Button), polja za unos slike na ekran aplikacije (Image), polja za čekiranje (CheckBox, Radio Button).

Jednostavnim prevlačenjem dizajner ima mogućnost da postavi objekte u neograničenoj količini. Svaki objekat može da se obriše sa ekrana, u bilo kom trenutku kreiranja aplikacije.

Prozor u gornjem levom uglu okruženja služi za personalizovanje ekrana. Prozor pruža mogućnost odabira pozadinske boje ekrana (Color). Ukoliko aplikacija poseduje više od jednog ekrana pruža se mogućnost odabira početnog ekrana (StartScreen).

Postoji mogućnost odabira orijentacije ekrana (Orientation). Mogućnost biranja da li će ekran biti statičan ili dinamičan se bira sa obeležavanjem kvadratića pod opcijom Static. Prikaz lenjira na gornjem i levom rubu ekrana pomaže korisniku da na lakši način napravi željene promere.

Data opcija se aktivira obeležavanjem kvadratića pod opcijom ShowRuler. Postoji mogućnost prikaza mreže na ekranu, koja služi samo kao orijentacija za dizajnera i pomaže mu $u$ lakšem postavljanju objekata na ekvidistantne razdaljine. Opcija se aktivira obeležavanjem kvadratića u rubrici Visible.

\subsection{Grafički interfejs edukativnog elektrofiziološkog sistema}

Krajnji izgled dizajnirane aplikacije može da se vidi na slikama 4, 5, 6. Početni ekran dizajnirane aplikacije predstavlja logo aplikacije. Logo aplikacije je uvezena slika formata .jpg, što može da se vidi na slici 4 .

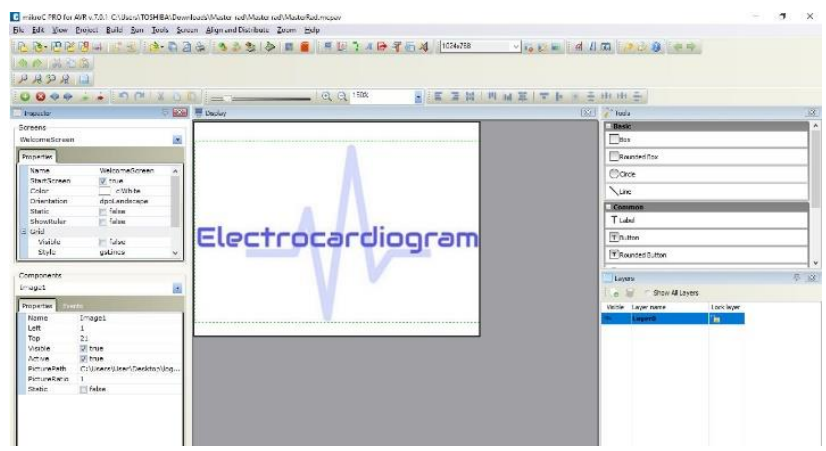

Slika 4. Početni ekran dizajnirane aplikacije 
Nakon početnog ekrana se pojavljuje Settings ekran koji na sebi ima naslov, tri tekstualne labele, 14 polja za čekiranje i dugme za prelazak na sledeći ekran, što može da se vidi naslici 7. Naslov je tipa bold, veličine 16, statičan i neaktivan. Tri labele koje predstavljaju podnaslove ( Select the channel, Amplitude resolution $[\mathrm{mV}]$, Time resolution [s] ) su tipa underline, veličine 8 , statični i neaktivni. Od 14 polja za čekiranje, tri polja su obeležena od početka pojavljivanja ekrana, a ostala polja nisu obeležena. Sva polja su aktivna. Dugme za nastavak na sledeći ekran je tipa OnClick i aktivan.

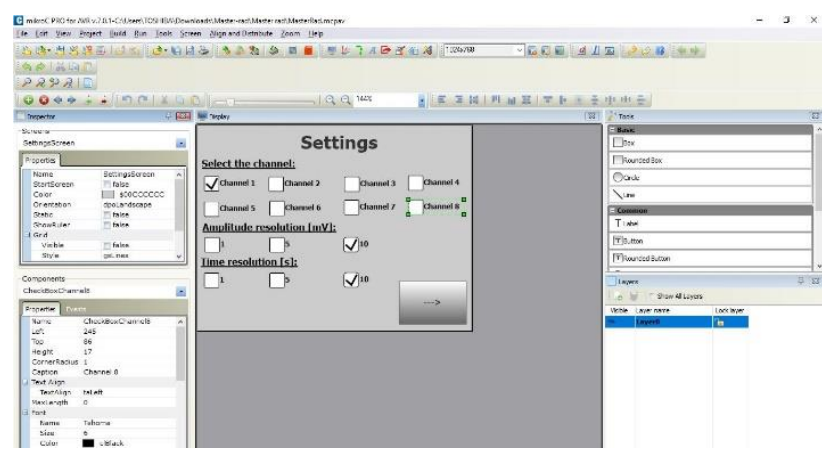

Slika 5. Settings ekran dizajnirane aplikacije

Nakon Settings ekrana se pojavljuje ekran za prikaz signala. Na datom ekranu se nalazi naslov (ECG signal Channel 1), koji je tipa bold, statičan i neaktivan, nalazi se polje na kom se iscrtava signal. Pozadina polja predstavljaju dva dugmeta, koja su spojena bez prostora između njih. Desno dugme je neaktivno, a dugme sa leve strane je atkivno i tipa OnDown. Nakon pritiska na dugme sa leve strane, aplikacija vraća korisnika na Settings ekran, bez obzira što se iscrtavanje signala nije završilo. Ispod donje ivice polja za iscrtavanje signala nalazi se vremenska osa, koju sačinjavaju labele. Sa leve strane polja za iscrtavanje signala nalazi se amplitudska osa koju takođe sačinjvaju labele.

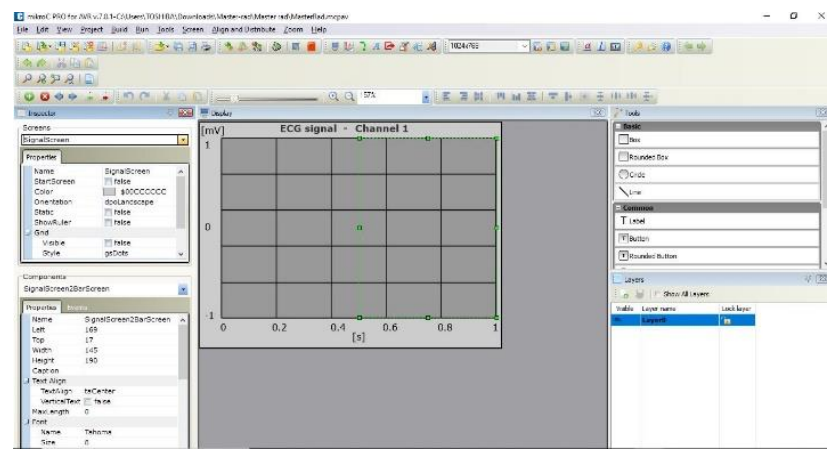

Slika 6. Ekran za prikazivanje snimljenog signala

\section{VERIFIKACIJA REALIZOVANOG EDUKATIVNOG ELEKTROFIZIOLOŠKOG SISTEMA}

Prvobitno je testiran uređaj sa dva tipa generatora:

1. Interni generator test signala integrisanog kola ADS1299

2. Eksterni test signal generator SIGI II EasyCap

Prilikom testirana aplikacije sa internim generatorom test signala dobijena je povorka pravougaonih četvrtki amplitude od -3.75 do $+3.75 \mathrm{mV}$. Na ekranu je prikazan signal na vremenskom intervalu od 5 sekundi. Primer dobijenog signala može da se uoči na slici 7 .

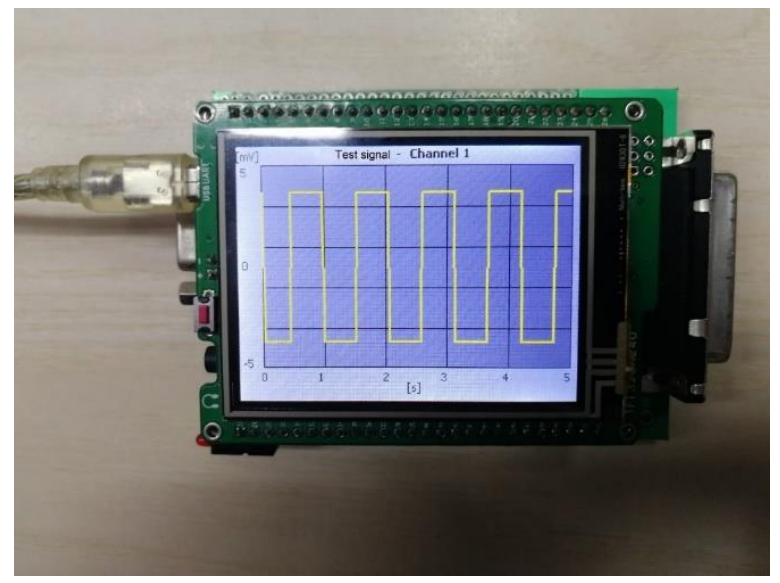

Slika 7. Izgled test signala dobijen internim test generatorom

\subsection{Rezultati dobijeni snimanjem realnih elektrofizioloških signala}

Kako bi snimanje EMG/EKG signala bilo uspešno potrebno je imati mikrokontroler ATXMega128A1 koji ima spušten program za izrvšavanje datog zadatka. Mikrokontroler je povezan sa računarom preko USB komunikacije. Potrebno je imati tri površinske elektrode koje su sa jedne strane postavljene na ruku/ruke pacijenta, a sa druge strane su povezane žično sa pločicom mikrokontrolera, što se vidi na slici 8 .

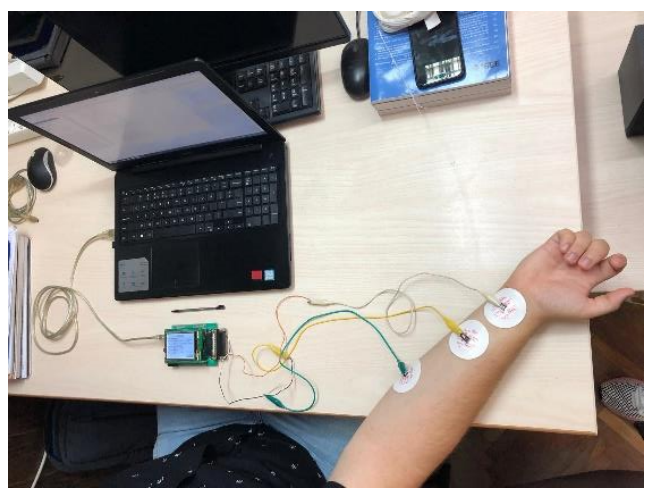

Slika 8. Proces snimanja EMG signala

Početni ekran aplikacije je bio dizajnirani logo koji se zadržavao na ekranu 3 sekunde i nakon toga je automatski nestajao sa ekrana.

Nakon početnog ekrana sledi "Settings" ekran. Dati ekran se nalazi na mikrokontroleru sve dok korsnik ne pritisne dugme za nastavak koji se nalazio u donjem desnom uglu ekrana. Na datom ekranu se nudi opcija odabira kanala snimanja signala. Korisnik može da izabere jedan od ponuđenih 8 kanala. Takođe ima mogućnost odabira amplitudske rezolucije ekrana koja je prikazana $\mathrm{u} \mathrm{mV}$ (milivoltima). U zavisnosti od korisničkog odabira amplitude signal se skalira i signal se prikazuje $u$ odabranoj razmeri. Korisniku se nudi opcija biranja amplitude signala od $1 \mathrm{mV}, 5 \mathrm{mV}$ I $10 \mathrm{mV}$. Poslednja opcija koju korisnik može da bira je vremenska rezolucija signala koja se prikazuje u sekundama. U zavisnosti da li je korisnik odabrao 1 sekundu, 5 ili 10, signal se u 
prikazuje u odabranoj vremenskoj brzini. Korisnik ima zadatak da obeleži jedan od polja u svakom području. Ukoliko se ne zadovolji dati uslov korisnik neće dobiti povratnu informaciju od mikrokontrolera. Korisnik takođe ne sme da obeleži više od jednog polja

Nakon pritiska na dugme za nastavak pojavljuje se treći ekran koji u zavisnosti od odabranih opcija na "Settings" ekranu prikazuje dati signal. U gornjem uglu ekrana stoji naslov koji prikazuje odabrani kanal snimanja.

Za snimanje EMG signala korišćena je bipolarna konfiguracija elektroda. Data konfiguracija obuhvata tri elektrode, pozitivnu, negativnu i DRL elektrodu. Na slici 9 je prikazan signal snimnjen sa prvog kanala. Vremenska rezolucija prikazivanja signala je 10 sekudni, stoga može da se uoče nekoliko mišićnih kontrakcija prilikom snimanja EMG signala. Amplitudska rezolucija ekrana je od -10 do $+10 \mathrm{mV}$.

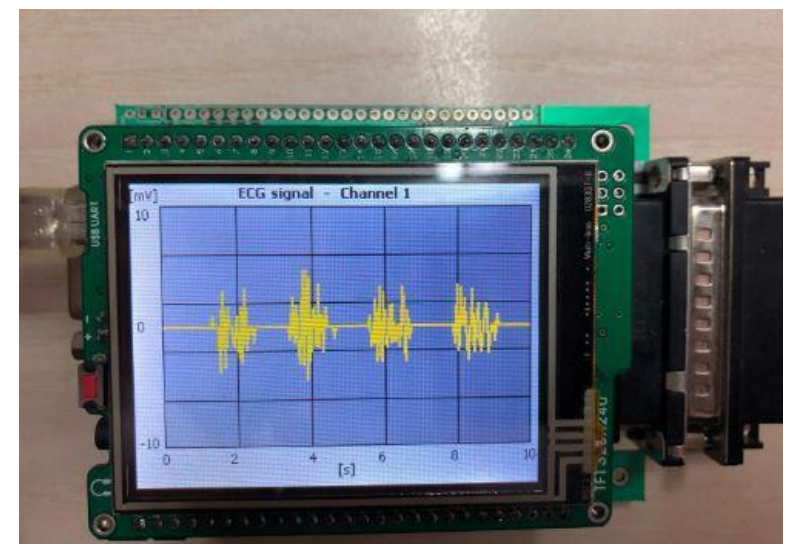

Slika 9. EMG signal

Prilikom snimanja EKG signala upotrebljen je prvi bipolarni odvod. Površinske elektrode se postavljaju na levu i desnu ruku. Pozitivna elektroda je postavljena na desnu ruku, a negativna i DRL elektroda su postavljene na levu ruku.

Na slici 10 prikazan je EKG signal. Vremenska rezolucija ekrana je 5 sekudni. Amplitudska rezolucija ekrana je od $1 \mathrm{do}+1 \mathrm{mV}$.

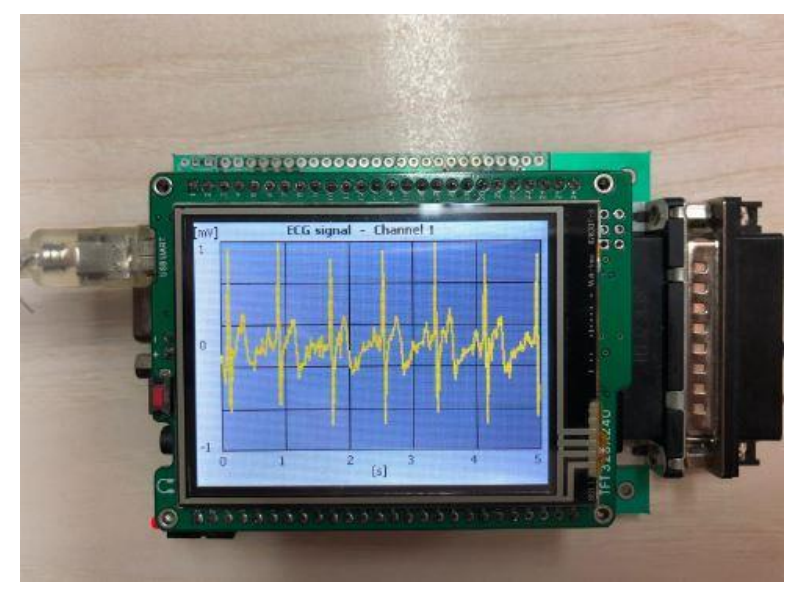

Slika 10. EKG signal

\section{ZAKLJUČAK}

Mogućnosti dizajniranja grafičkih interfejsa za projektante su neiscrpne. Uticaj interfejsa na korisnike je veoma velik. Razvoj grafičkog interfejsa u medicini pomaže korisniku da se zainteresuje za sopstveno zdravtsveno stanje. Posedovanjem prenosivog interfejsa pruža se mogućnost merenja elektrofizioloških signala van zdravstvenih ustanova.

Razvijeni edukativni elektrofiziološki uređaj omogućava korisniku, a pre svega studentima da steknu praktično znanje iz oblasti elektrofiziologije i akvizicionih mernih sistema. Pruža se mogućnost merenja realnih elektrofizioloških signala. Uređaj je jednostavan za upotrebu i prenosiv.

Performanse uređaja se mogu unaprediti uvođenjem bežične komunikacije sa računarom. Mogućnost razvoja merenja impedanse interfejsa elektroda - tkivo bi dodatno unapredilo uređaj. Ukoliko bi se dodalo merenje oksigenisanosti krvi u organizmu tada bi performanse uređaja bile potpune. Kvalitet usluga ima rastući značaj kako za korisnika tako i za proizvođače.

Težnja za sveprisutnim računarskim sistemima i zahtevi tržišta neprekidno povećavaju značaj univerzalnosti i upotrebljivosti interfejsa. Savršenstvo je u jednostavnosti.

\section{LITERATURA}

[1] Vikipedija, slobodna enciklopedija, Grafički korisnički interfejsi.

[2] Ben Sheiderman, Catherine Plaisant, Designing the user interface, University of Maryland 2005.

[3] Orawit Thinnukool, The user's satisfaction of graphic user interface in designing for health care mobile applicaton, Chiang Mai University 2017.

[4] Vikipedija, slobodna enciklopedija, Elektrokardiogram.

\section{Kratka biografija:}

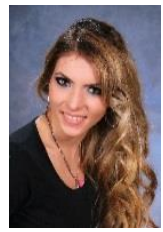

Žaklina Stojšin rođena je u Subotici 1995. godine Master rad na Fakultetu tehničkih nauka iz oblasti Elektrotehnike i računarstva je odbranila 2019. godine.

Kontakt: zanastojsin@yahoo.com 